CLINICAL STUDY

\title{
Adiposity, estradiol, and genetic variants of steroid-metabolizing enzymes as determinants of bone mineral density
}

\author{
Maria T Zarrabeitia ${ }^{1}$, Jose L Hernandez ${ }^{2}$, Carmen Valero ${ }^{2}$, Ana Zarrabeitia ${ }^{2}$, Jose A Amado ${ }^{2}$, Jesus Gonzalez- \\ Macias $^{2}$ and Jose A Riancho ${ }^{2}$ \\ ${ }^{1}$ Unit of Legal Medicine and ${ }^{2}$ Department of Internal Medicine, Hospital U.M. Valdecilla, University of Cantabria, Santander 39008, Spain \\ (Correspondence should be addressed to J A Riancho; Email: rianchoj@unican.es)
}

\begin{abstract}
Objectives: Bone mineral density (BMD) is a complex trait resulting from the interplay of genetic and acquired factors. The objective of this study was to explore the influence of several anthropometric, lifestyle, genetic, and hormonal factors on BMD and analyze the possible differences in men and women. Methods: We studied 572 individuals over 50 years of age (381 postmenopausal women and $191 \mathrm{men}$ ). Lumbar spine and femoral neck BMD were measured by dual energy x-ray absorptiometry. The free estrogen index (FEI) was calculated as the ratio of serum estradiol to sex hormone binding globulin in 241 individuals. Three polymorphisms in the genes coding for 17-hydroxylase/liase, sulfotransferase, and $5 \alpha$-reductase were studied in DNA isolated from blood cells.

Results: Body mass index was strongly correlated to spine and femoral BMD both in women and in men $(r=0.32-0.49 ; P<0.001)$. FEI was also independently correlated with spine BMD in both sexes $(r=$ 0.23 and $0.34, P<0.01)$, and with femoral neck in women $(r=0.30)$. Women with $\mathrm{G}$ alleles of the sulfotransferase gene tended to have higher spine BMD than those with $\mathrm{C}$ alleles $(P=0.025)$. No other genotype-related differences in BMD were found.

Conclusions: In conclusion, the results of this study point toward body weight and estradiol levels as major factors determining BMD both in women and in men. A common polymorphism of the sulfotransferase gene also appears to be associated to spine BMD in women.
\end{abstract}

European Journal of Endocrinology 156 117-122

\section{Introduction}

Bone mineral density (BMD) is a complex trait, resulting from the interplay of both genetic and acquired influences, including among the latter nutritional, hormonal, and physical factors. Sex hormones play a critical role in bone homeostasis and the decline in estrogen availability after the menopause is a central factor in the development of postmenopausal osteoporosis (1). Given their role in bone homeostasis, genes related to the metabolism of sex steroids are likely candidates to contribute to the hereditary influence on BMD.

It has been suggested, from the results of a number of family and twin studies, that genetic factors may explain about to $30-80 \%$ of the variability of BMD and fracture risk (2, 3). Nevertheless, establishing the relative importance of genetic and environmental factors is a difficult task, not only because many factors may be involved, but also because of the interactions among them. We planned this study to explore the influence of several anthropometric, lifestyle, genetic, and hormonal factors on BMD and analyze the possible differences in men and women. In particular, we decided to study three polymorphisms of genes coding for enzymes involved in the metabolism of sex steroids which have been previously found associated to certain hormonesensitive conditions, namely 17-hydroxylase, 5 $\alpha$ reductase, and sulfotransferase (4-8).

\section{Material and methods}

\section{Subjects}

We included 572 individuals over 50 years of age (381 postmenopausal women and 191 men). They were volunteers recruited by voice and written announcements from various sources to prevent a preferential selection bias (hospital workers, civic associations, religious groups, and geriatric residences) and patients with primary osteoporosis. All were living in Cantabria, a region in Northern Spain with a population of 530000. They were interviewed by one of the investigators in order to check the absence of exclusion criteria. Subjects taking bisphosphonates, corticosteroids, antiepileptics, thiazides, estrogens, or other drugs known to modify bone mass, as well as those with past or present diseases known to affect bone metabolism, poor mental or physical performance status, or non-Spanish ancestry 
were excluded. Causes of secondary osteoporosis were excluded by clinical examination and laboratory tests (including complete blood count, ESR, serum biochemical profile, protein electrophoresis, thyroid hormones, and parathyroid hormone). Height was measured using a wall-mounted stadiometer. Weight was measured with upright balance scales. Calcium intake from dairy products was estimated by a questionnaire (9). Individuals were considered to exercise if they currently performed recreational weight-bearing activities or walked at least $4 \mathrm{~km} /$ day. Alcohol intake was defined as a daily intake of more than $10 \mathrm{~g}$. Subjects were regarded as smokers if they had a present or past history of smoking at least 5 cigarettes/day for a minimum of 5 years. The study was approved by the Institutional Ethics Committee and subjects gave informed consent.

BMD was determined by anterior-posterior dual energy x-ray absorptiometry (DXA) scans at the lumbar spine (L2-L4) and the femoral neck using a Hologic QDR 4500 densitometer (Hologic, Waltham, MA, USA). The coefficient of variation measuring a standard phantom with repositioning was $<1 \%$. Volumetric BMD was estimated by modeling vertebrae and the femoral neck as cylinders with previously published formulas (10).

\section{Serum estradiol}

Hormone levels were measured in a random subset of subjects (177 women and 64 men). Estradiol was determined by an ultrasensitive RIA (Diagnostic Systems Laboratories, Webster, TX, USA), with a sensitivity of $4 \mathrm{pmol} / \mathrm{l}$ and a coefficient of variation (CV) of 4-9\%. Sex hormone binding globulin (SHBG) was determined by an ELISA (IBL, Hamburg, Germany) with a sensitivity of $0.2 \mathrm{nmol} / \mathrm{l}$ and $\mathrm{CV}$ of $9 \%$. The free estrogen index (FEI) was calculated as the molar ratio of total estradiol to SHBG.

\section{Genetic analysis}

Genomic DNA was obtained from the peripheral blood using a commercial kit, according to the manufacturer's instructions (Qiagen).

Three polymorphic loci in genes related to sex steroid metabolism that had been previously suggested to be related with hormone activity were analyzed.

a. CYP17. This gene codes for the $17 \alpha$-hydroxylase/17,20-lyase. A T/C single nucleotide polymorphism (SNP) situated in the $5^{\prime}$ region of the CYP17 gene, which creates a Sp-1 site at position -34 , has been associated with differences in transcriptional activity $(11,12)$.

b. SULT1A1. The gene codes for sulfotransferase, an enzyme involved the catabolism of steroids and other products. We studied a $\mathrm{C} / \mathrm{G}$ polymorphism in codon 213, resulting in an arginine to histidine change, which reduces the catalytic activity (13). c. SRD5A2. This gene codes for $5 \alpha$-reductase type II, the enzyme converting testosterone into the active compound dihydrotestosterone. We studied a G/C non-synonymous polymorphism at codon 89 (V89L), which has been associated to serum sex steroids and hormone-dependent cancers in some studies (6-8).

CYP17 genotyping was performed by a procedure based on the exonuclease activity of Taq DNApolymerase, using allele-specific Taqman probes labeled with VIC and FAM. Primers and probes were designed by the manufacturer with Primer Express software (Taqman Assays-on-Demand, Applied Biosystems, Foster City, CA, USA). After amplification in an ABI9700 thermal cycler (Applied Biosystems), the fluorescence was read in an ABI7300 sequence detector. SRD5A2 and SULT1A1 loci were amplified by PCR with the primers reported by Latil (14) and Seth respectively (13). The PCR products were digested with RsaI (SRD5A2) or HaeII (SULT1A1), electrophoresed through agarose gels, and stained with ethidium bromide. Random samples were analyzed twice to check for consistency of results. DNA analysis was performed blind of other results.

\section{Data analysis}

The relationship between anthropometric variables and DXA was analyzed by linear regression, after sexstratification. Partial correlation coefficients were computed to analyze the independent relationship of different continuous factors with BMD. Genetic factors were analyzed at the genotype level. The association of genotypes with BMD was tested by analysis of variance and covariance, with adjustment for potential confounding variables. All analyses were two-tailed and $P$ values $<0.05$ were considered statistically significant. The SPSS software was used (SPSS Inc, Chicago, IL, USA).

\section{Results}

As expected, BMD was significantly different in men and women, therefore data were analyzed separately. Their main characteristics are shown in Table 1.

The main results of the univariate analysis are shown in Table 2. Body weight, height, and body mass index (BMI) were positively correlated to BMD, both at the spine and at the femoral neck (Fig. 1). That relationship was not just a consequence of differences in the size of bones, as BMI was also significantly correlated to the estimated volumetric BMD at both regions and in both sexes (all $P$ values <0.001). Calcium intake, physical activity, tobacco, and alcohol consumption were not associated to BMD. Serum free estradiol, assessed by the FEI, was also significantly associated to hip and spine BMD in women, and to spine BMD in men (Table 2 and Fig. 2). 
Table 1 Characteristics of study subjects.

\begin{tabular}{lcc}
\hline & Women & Men \\
\hline Age (year) & $68 \pm 8$ & $65 \pm 8$ \\
Duration of menopause (year) & $19 \pm 9$ & - \\
Height (cm) & $154 \pm 6$ & $167 \pm 7$ \\
Body weight (kg) & $65 \pm 10$ & $78 \pm 11$ \\
Body mass index (kg/m²) & $27.3 \pm 4.0$ & $28.2 \pm 3.4$ \\
Calcium intake (mg) & $683 \pm 374$ & $663 \pm 412$ \\
Alcohol intake (\%) & 9 & 54.2 \\
Smoking (\%) & 12 & 50.6 \\
Exercise (\%) & 29 & 55 \\
Estradiol (pmol/l) & $100 \pm 30$ & $174 \pm 63$ \\
SHBG (nmol/l) & $60 \pm 25$ & $48 \pm 17$ \\
FEl (pmol/nmol) & $2.0 \pm 1.2$ & $4.2 \pm 2.6$ \\
\hline
\end{tabular}

SHBG, sex hormone-binding globulin; FEI, free estrogen index.

In women, age-adjusted FEI was positively related to BMI (partial $r=0.17, P=0.026$ ) and negatively to age (partial $r=-0,16, P=0.04$ ). In men, those relationships were not statistically significant.

The independent association of those factors with BMD was studied by multivariate regression models. In women, both BMI and FEI were independently related to spine and femoral neck BMD. The partial correlation coefficients between BMI and BMD, controlling for the influence of FEI and age, were 0.32 and 0.37 (both $P<$ $0.001)$ at the spine and the femoral neck respectively. The correlation coefficients between BMD and FEI, controlling for the influence of BMI and age, were 0.23 $(P=0.003)$ and $0.30(P<0.001)$, at the spine and the femoral neck, respectively.

In men, both BMI and FEI were independently associated to spine BMD. BMI, but not FEI, was also significantly related to femoral neck BMD. The partial correlation coefficients between BMI and BMD, controlling for the influence of FEI and age, were 0.40 and 0.49 (both $P<0.001$ ) at the spine and the femoral neck, respectively. After correction for the effects of age and BMI, the partial correlation coefficients between FEI and BMD were $0.34(P=0.008)$ and $0.19(P=0.15)$, at the spine and the femoral neck, respectively.

In general linear models including BMD as the dependent variable and sex, BMI, and FEI as covariates, there were no significant interactions between sex and FEI on BMD $(P>0.2)$. There was an interaction between sex and BMI on femoral neck BMD $(P=0.004)$, but not on spine BMD $(P>0.3)$. Therefore, the analysis suggested a stronger association of BMI and femoral neck BMD in men than in women, without statistical evidence for significant sex-related differences in the other associations tested.

Allelic frequencies of the polymorphisms studied are shown in Table 3. There was no evidence for departure from the Hardy-Weinberg equilibrium. In women, G alleles of the SULT1A1 gene (causing a reduction of the catalytic activity) tended to be associated to a higher spine BMD (Table 4). Polymorphisms of CYP17 and $S R D 5 A 2$ genes were not associated to spine BMD (not shown). No polymorphism was significantly associated to BMD at the femoral neck, either individually (Table 4) or in combination models including the alleles present at various loci. There was no evidence for interaction between the genetic polymorphisms and the FEI. Likewise, there was no evidence for interaction with body weight, thus similar results were observed when individuals were stratified according to BMI (not shown).

\section{Discussion}

In this study, we found a strong relationship between BMI and BMD at the hip and the spine, in postmenopausal women as well as in men. This confirms previous results and emphasizes the importance of an adequate body weight to maintain skeletal homeostasis (15). Multiple mechanisms may be involved. The skeleton of people with high body weight is obviously exposed to higher loads, and the bone anabolic effect of physical forces is well known (16). On the other hand, for a given body constitution, a higher BMI means higher fat mass, which may have particular positive effects on bone mass. Although we do not have data about the body components of these subjects, a number of studies have suggested that fat mass may be more directly related to bone mass than lean mass (15). Such relationship between fat mass and bone mass can be mediated by different mechanisms, including genetic factors influencing body habitus $(17,18)$ and a variety of chemical factors. The adipose tissue synthesizes a number of circulating factors which may influence bone homeostasis, by direct and indirect mechanisms (19).

Table 2 Relationship between bone mineral density (BMD) and several factors in women and men ( $\beta$ standardized regression coefficients).

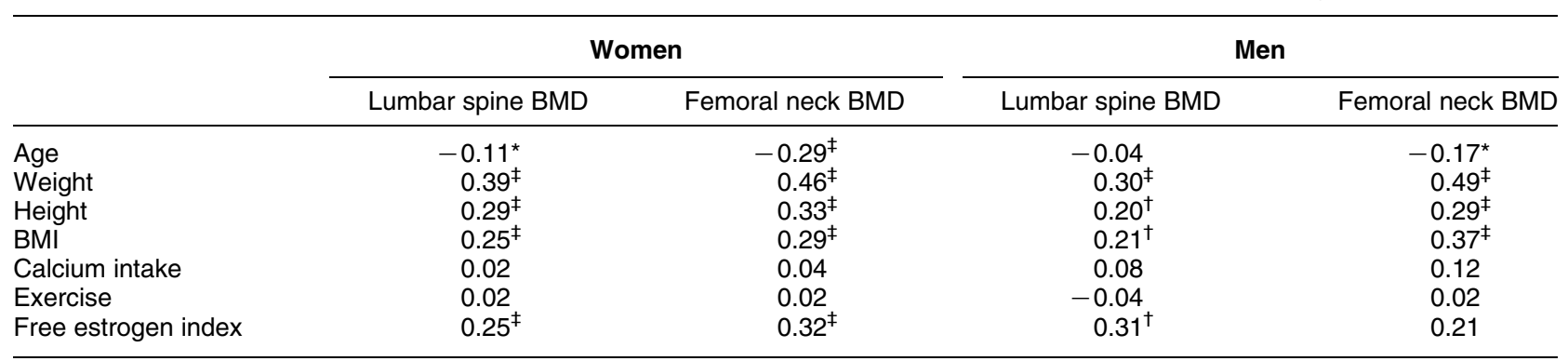

BMI, body mass index; ${ }^{\star} P<0.05,{ }^{\dagger} P<0.01,{ }^{\ddagger} P<0.001$. 

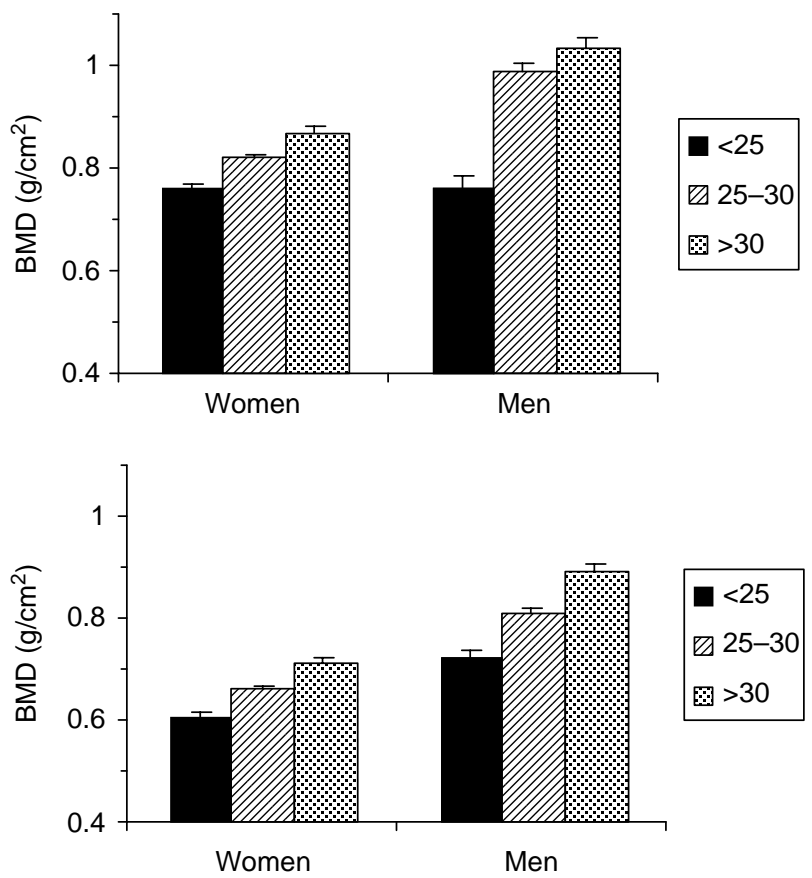

Figure 1 Age-adjusted bone mineral density (BMD) $\left(\mathrm{g} / \mathrm{cm}^{2}\right)$ according to body mass index (BMI) in women and men (upper panel, spine BMD; lower panel, femoral neck BMD). BMI: <

$25 \mathrm{~kg} / \mathrm{m}^{2}$, black bars; $25-30 \mathrm{~kg} / \mathrm{m}^{2}$, dashed bars; $>30 \mathrm{~kg} / \mathrm{m}^{2}$, dotted bars.

Probably the most extensively studied is leptin. Leptin has direct effects on bone cells, but it can also modulate bone metabolism through the interaction with the $\mathrm{CN}$ (20).

The critical role of estrogens in bone homeostasis is widely recognized (1), and one of its consequences is the loss of bone occurring after the menopause, when the gonadal function ceases. The aromatization of androgenic precursors is the main source of estrogens in men and women after the menopause. A variety of human

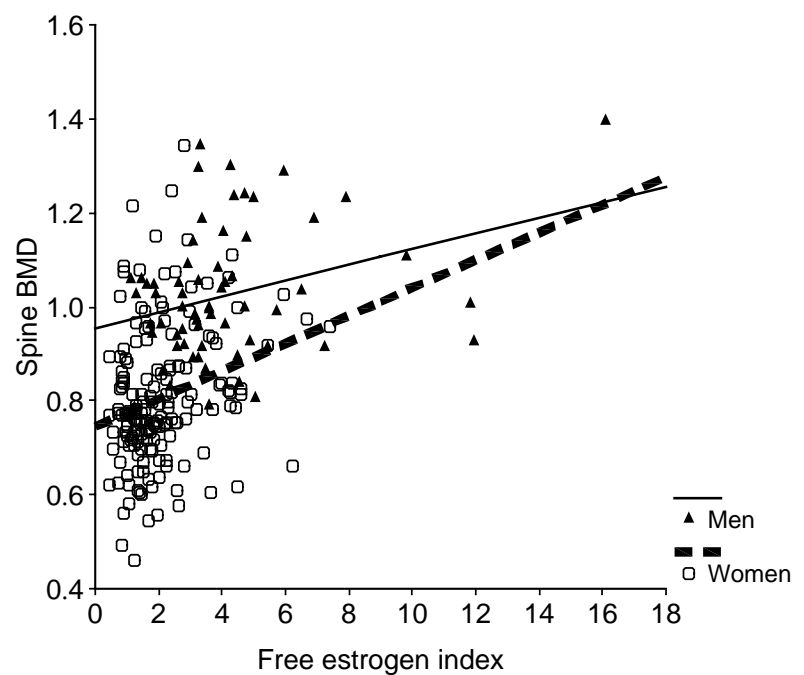

Figure 2 Relationship between free estrogen index and spine BMD in women (open circles, dotted line) and men (closed triangles, continuous line).
Table 3 Allele frequencies (\%).

\begin{tabular}{lcc}
\hline Gene (SNP) & Allele & Frequency \\
\hline CYP17 (rs743572) & T & 57.6 \\
SULT1A1 (rs928861) & C & 42.4 \\
& C & 69.7 \\
SRD5A2 (rs523349) & G & 30.3 \\
& V & 82.6 \\
& L & 27.4 \\
\hline
\end{tabular}

tissues have been shown to express the aromatase gene. Apart from the gonads, aromatase activity and/or RNA transcripts have been detected in muscle, fat, bone, nervous tissue, and several tumors (21). The adipose tissue is usually regarded as a major source of estrogens after the menopause and it may represent another mechanism by which fat mass influences bone. In this study, we found a positive correlation between BMI and free estrogen levels in women, which is consistent with that contention. On their own, estrogen levels correlated with BMD, particularly at spine, both in women and in men. These results confirm other studies pointing toward an important role of estrogen not only in women but also in adult and elderly men (2225). However, the relationship between BMI and BMD was independent, at least partially, of estrogen levels, thus emphasizing the multiple mechanisms involved in the association between BMI and bone mass.

Although the overall importance of genetic factors in bone mass determination is out of doubt (2), the genes being actually responsible for the BMD variability are unclear. The role of a number of candidate genes has been explored. Among them, those related to sex steroid metabolism are particularly attractive, for the critical role of those hormones in bone homeostasis. In fact, we and others have reported an association between aromatase gene and bone mass (26-28). Polymorphisms of the CYP17 gene have been related to BMD in some studies $(4,29,30)$, but, as in the present study, other authors did not find an association $(12,31)$. The frequencies of the CYP17 and the two other polymorphisms in this study were similar to those reported in other Caucasian populations $(6,13,32,33)$.

Sulfotransferase is involved in estrogen catabolism. The polymorphism here studied appears to result in differences in enzyme activity $(13,34)$, but we are not aware of previous studies of the relationship of this gene with BMD. In the present study, we found a higher spine BMD in women with $G$ alleles, which appear to be associated to reduced enzymatic activity and, therefore, theoretically slower steroid catabolism. We did not find statistically significant differences in serum estradiol between women with $\mathrm{G}$ and $\mathrm{C}$ alleles (not shown), but it does not exclude the existence of differences in estrogen bioavailability at the tissue level. Nevertheless, there was no relationship between femoral neck BMD and sulfotransferase alleles. Therefore, given the risk of type 
Table 4 Age- and body mass index-adjusted femoral neck bone mineral density according to genotypes (mean, 95\% confidence interval and $P$ values for the differences across genotypes of each locus).

\begin{tabular}{|c|c|c|c|c|c|c|c|c|}
\hline & \multicolumn{4}{|c|}{ Lumbar spine } & \multicolumn{4}{|c|}{ Femoral neck } \\
\hline & Women & $P$ & Men & $P$ & Women & $P$ & Men & $P$ \\
\hline \multicolumn{9}{|c|}{ CYP17 } \\
\hline TT & $0.788(0.763-0.813)$ & 0.16 & $1.000(0.966-1.035)$ & 0.84 & $0.647(0.630-0.664)$ & 0.66 & $0.811(0.780-0.842)$ & 0.77 \\
\hline CT & $0.818(0.796-0.840)$ & & $0.993(0.962-1.023)$ & & $0.653(0.638-0.668)$ & & $0.827(0.789-0.854)$ & \\
\hline $\mathrm{CC}$ & $0.818(0.786-0.849)$ & & $1.009(0.960-1.059)$ & & $0.659(0.638-0.681)$ & & $0.821(0.776-0.866)$ & \\
\hline \multicolumn{9}{|c|}{ SULT1A1 } \\
\hline $\mathrm{GG}$ & $0.849(0.789-0.908)$ & 0.02 & $0.987(0.889-1.084)$ & 0.78 & $0.650(0.609-0.692)$ & 0.55 & $0.844(0.763-0.924)$ & 0.47 \\
\hline CG & $0.807(0.783-0.830)$ & & $0.982(0.947-1.017)$ & & $0.653(0.637-0.669)$ & & $0.821(0.792-0.850)$ & \\
\hline $\mathrm{CC}$ & $0.782(0.759-0.805)$ & & $1.000(0.962-1.038)$ & & $0.641(0.625-0.656)$ & & $0.801(0.769-0.832)$ & \\
\hline \multicolumn{9}{|c|}{ SRDA2 } \\
\hline LL & $0.753(0.699-0.808)$ & 0.12 & $0.991(0.921-1.061)$ & 0.72 & $0.642(0.605-0.678)$ & 0.06 & $0.789(0.725-0.854)$ & 0.51 \\
\hline VL & $0.807(0.780-0.833)$ & & $0.989(0.955-1.023)$ & & $0.656(0.638-0.674)$ & & $0.832(0.800-0.863)$ & \\
\hline VV & $0.759(0.758-0.800)$ & & $1.007(0.977-1.036)$ & & $0.628(0.614-0.644)$ & & $0.821(0.794-0.848)$ & \\
\hline
\end{tabular}

I error when multiple tests are performed, these results should require confirmation in other populations.

Polymorphisms of $5 \alpha$-reductase may influence the conversion of testosterone into the more active $5 \alpha$ dihydrotestosterone. Bone cells express androgen receptors and respond to androgens. They also express a number of enzymes of the sex hormone biosynthetic pathway, including $5 \alpha$-reductase (35). We did not find an association between the polymorphism studied and $\mathrm{BMD}$, despite the fact that it is a non-synonymous functional SNP (6). This negative result may be related to the particular tissue expression profile of $5 \alpha$ reductase. Whereas we studied an SNP of the type II $5 \alpha$-reductase gene, the type I gene may be preferentially expressed in the bone tissue (36).

This study has some limitations. As already mentioned, the lack of body composition data did not allow to study the relative influence of lean and fat components on BMD. It should also be mentioned that the moderate study size does not permit to exclude a small influence of genetic factors on bone. For instance, according to the allele frequencies found, the study had more than $95 \%$ power to detect a genetic influence causing a $10 \%$ difference in BMD in either sex. However, the power to detect a $5 \%$ difference in BMD was reduced to $75-92 \%$ in females and to $50-75 \%$ in males. Similarly, the power of the association analysis of estrogen levels was $81 \%$ in males and more than 95\% in women, to detect a correlation of $r^{2}=10 \%$, but only 50 and $90 \%$ respectively, to detect a correlation with $r^{2}=5 \%$. Also, the lack of association between the polymorphisms here studied and BMD does not exclude the possibility that other variations in those genes might influence bone mass. Studies of several tag polymorphisms capturing the whole gene variation would be necessary to further clarify this issue.

In conclusion, the results of this study point toward body weight and estradiol levels as major factors determining BMD both in women and in men. Genetic factors are also known to play an important role and we found a statistically significant association between a non-synonymous polymorphism of the SULT1A1 gene and spine BMD in women.

\section{Acknowledgements}

Supported by grants from Fondo de Investigaciones Sanitarias (FIS PI 020063 and PI 040028).

\section{References}

1 Riggs BL, Khosla S \& Melton LJ III. Sex steroids and the construction and conservation of adult skeleton. Endocrine Reviews 200223 279-302.

2 Ralston SH. Genetic control of susceptibility to osteoporosis. Journal of Clinical Endocrinology and Metabolism 200287 2460-2466.

3 Michaelsson K, Melhus H, Ferm H, Ahlbom A \& Pedersen NL. Genetic liability to fractures in the elderly. Archives of Internal Medicine 2005165 1825-1830.

4 Tofteng CL, Abrahamsen B, Jensen JE, Petersen S, Teilmann J, Kindmark A, Vestergaard P, Gram J, Langdahl BL \& Mosekilde L. Two single nucleotide polymorphisms in the CYP17 and COMT genes - relation to bone mass and longitudinal bone changes in postmenopausal women with or without hormone replacement therapy. The Danish Osteoporosis Prevention Study. Calcified Tissue International 200475 123-132.

5 Kittles RA, Panguluri RK, Chen W, Massac A, Ahaghotu C, Jackson A, Ukoli F, Adams-Campbell L, Isaacs W \& Dunston GM. Cyp 17 promoter variant associated with prostate cancer aggressiveness in African Americans. Cancer Epidemiology, Biomarkers and Prevention 200110 943-947.

6 Scorilas A, Bharaj B, Giai M \& Diamandis EP. Codon 89 polymorphism in the human 5 alpha-reductase gene in primary breast cancer. British Journal of Cancer 200184 760-767.

7 Hsing AW, Chen C, Chokkalingam AP, Gao YT, Dightman DA, Nguyen HT, Deng J, Cheng J, Sesterhenn IA, Mostofi FK, Stanczyk FZ \& Reichardt JK. Polymorphic markers in the SRD5A2 gene and prostate cancer risk: a population-based casecontrol study. Cancer Epidemiology, Biomarkers and Prevention 2001 10 1077-1082.

8 Söderström T, Wadelius M, Andersson SO, Johansson JE, Johansson S, Granath F \& Rane A. $5 \alpha$-Reductase 2 polymorphisms as risk factors in prostate cancer. Pharmacogenetics 200212 307-312. 
9 Docio S, Riancho JA, Perez A, Olmos JM, Amado JA \& GonzalezMacias J. Seasonal deficiency of vitamin D in children: a potential target for osteoporosis-preventing strategies? Journal of Bone and Mineral Research 199813 544-548.

10 Duan Y, Beck TJ, Wang XF \& Seeman E. Structural and biomechanical basis of sexual dimorphism in femoral neck fragility has its origins in growth and aging. Journal of Bone and Mineral Research $2003 \mathbf{1 8} 1766-1774$.

11 McCann SE, Moysich KB, Freudenheim JL, AMbrosone CB \& Shields PG. The risk of breast cancer associated with dietary lignans differs by CYP17 genotype in women. Journal of Nutrition $20021323036-3041$.

12 Zmuda JM, Cauley JA, Kuller LH \& Ferrell RE. A common promoter variant in the cytochrome P450c17alpha (CYP17) gene is associated with bioavailability testosterone levels and bone size in men. Journal of Bone and Mineral Research 20015 911-917.

13 Seth P, Lunetta KL, Bell DW, Gray H, Nasser SM, Rhei E, Kaelin CM, Iglehart DJ, Marks JR, Garber JE, Haber DA \& Polyak K. Phenol sulfotransferases: hormonal regulation, polymorphism, and age of onset of breast cancer. Cancer Research $2000606859-6863$.

14 Latil AG, Azzouzi R, Cancel GS, Guillaume EC, Cochan-Priollet B, Berthon PL \& Cussenot O. Prostate carcinoma risk and allelic variants of genes involved in androgen biosynthesis and metabolism pathways. Cancer 200192 1130-1137.

15 Reid IR. Relationships among body mass, its components, and bone. Bone 200231 547-555.

16 Frost HM, Ferretti JL \& Jee WS. Perspectives: some roles of mechanical usage, muscle strength, and the mechanostat in skeletal physiology, disease, and research. Calcified Tissue International $1998621-7$.

17 Deroo BJ \& Korach KS. Estrogen receptors and human disease. Journal of Clinical Investigation $2006 \mathbf{1 1 6} 561-570$.

18 Huang QY, Shen H, Deng HY, Conway T, Davies KM, Li JL, Recker RR \& Deng HW. Linkage and association of the CA repeat polymorphism of the IL6 gene, obesity-related phenotypes, and bone mineral density (BMD) in two independent Caucasian populations. Journal of Human Genetics $2003 \mathbf{4 8} 430-437$.

19 Ronti T, Lupattelli G \& Mannarino E. The endocrine function of adipose tissue: an update. Clinical Endocrinology 2006 64 355-365.

20 Hamrick MW. Leptin, bone mass, and the thrifty phenotype. Journal of Bone and Mineral Research 200419 1607-1611.

21 Gruber CJ, Tschugguel W, Schneeberger C \& Huber JC. Mechanisms of disease: production and actions of estrogens. New England Journal of Medicine 2002346 340-352.

22 Rapuri PB, Gallagher JC \& Haynatzki G. Endogenous levels of serum estradiol and sex hormone binding globulin determine bone mineral density, bone remodeling, the rate of bone loss, and response to treatment with estrogen in elderly women. Journal of Clinical Endocrinology and Metabolism 200489 4954-4962.

23 Van Pottelbergh I, Goemaere S \& Kaufman JM. Bioavailable estradiol and aromatase gene polymorphism are determinants of bone mineral density changes in men over 70 years of age. Journal of Clinical Endocrinology and Metabolism $2003 \mathbf{8 8} 3075-3081$.

24 Van Pottelbergh I, Goemaere S, Zmierczak H \& Kaufman JM. Perturbed sex steroid status in men with idiopathic osteoporosis and their sons. Journal of Clinical Endocrinology and Metabolism 200489 4949-4953.

25 Goderie-Plomp HW, van der KM, de Ronde W, Hofman A, de Jong FH \& Pols HA. Endogenous sex hormones, sex hormone-binding globulin, and the risk of incident vertebral fractures in elderly men and women: the Rotterdam Study. Journal of Clinical Endocrinology and Metabolism 200489 3261-3269.

26 Zarrabeitia MT, Hernandez JL, Valero C, Zarrabeitia AL, GarciaUnzueta MT, Amado JA, Gonzalez-Macias J \& Riancho JA. A common polymorphism in the $5^{\prime}$-untranslated region of the aromatase gene influences bone mass and fracture risk. European Journal of Endocrinology 2004150 699-704.

27 Gennari L, Masi L, Merlotti D, Picarriello L, Falchetti A, Tanini A, Mavilia C, Del Monte F, Gonnelli S, Lucani B, Gennari C \& Brandi ML. A polymorphic CYP19 TTTA repeat influences aromatase activity and estrogen levels in elderly men: effects on bone metabolism. Journal of Clinical Endocrinology and Metabolism 200489 2803-2810.

28 Riancho JA, Zarrabeitia MT, Valero C, Sanudo C, Mijares V \& Gonzalez-Macias J. A gene-to-gene interaction between aromatase and estrogen receptors influences bone mineral density. European Journal of Endocrinology 2006155 53-59.

29 Somner J, McLellan S, Cheung J, Mak YT, Frost ML, Knapp KM, Wierzbicki M, Fogelman I, Ralston SH \& Hampson GN. Polymorphisms in the P450 c17(17-hydroxylase/17,20-lyase) and P450 c19 (aromatase) genes: association with serum sex steroid concentrations and bone mineral density in postmenopausal women. Journal of Clinical Endocrinology and Metabolism 200489 344-351.

30 Yamada Y, Ando F \& Shimokata H. Association of polymorphisms in CYP17A1, MTP, and VLDLR with bone mineral density in community-dwelling Japanese women and men. Genomics 2005 $8676-85$.

31 Chen HY, Chen WC, Hsu CM, Tsai FJ \& Tsai CH. Tumor necrosis factor alpha, CYP 17, urokinase, and interleukin 10 gene polymorphisms in postmenopausal women: correlation to bone mineral density and susceptibility to osteoporosis. European Journal of Obstetrics, Gynecology, and Reproductive Biology 2005 $12273-78$.

32 Sharp L, Cardy AH, Cotton SC \& Little J. CYP17 gene polymorphisms: prevalence and associations with hormone levels and related factors. A HuGE review. American Journal of Epidemiology 2004160 729-740.

33 Coughtrie MW, Gilissen RAKJ, Shek B, Strange RC, Fryer AA, Jones PW \& Bamber DE. Phenol sulphotransferases SULT1A1 polymorphism: molecular diagnosis and alelle frequencies in Caucasian and African populations. Biochemical Journal 1999337 45-49.

34 Suzuki T, Miki Y, Nakata T, Shiotsu Y, Akinaga S, Inoue K, Ishida T, Kimura M, Moriya T \& Sasano H. Steroid sulfatase and estrogen sulfotransferase in normal human tissue and breast carcinoma. Journal of Steroid Biochemistry and Molecular Biology $200386449-454$.

35 Compston J. Local biosynthesis of sex steroids in bone. Journal of Clinical Endocrinology and Metabolism 200287 5398-5400.

36 Issa S, Schnabel D, Feix M, Wolf L, Schaefer HE, Russell DW \& Schweikert HU. Human osteoblast-like cells express predominantly steroid 5alpha-reductase type 1. Journal of Clinical Endocrinology and Metabolism $2002 \mathbf{8 7} 5401-5407$.

Received 30 August 2006

Accepted 11 October 2006 